\title{
Cesarean Section Indications and Prognosis in Adolescents Girls at the Mother-Child Pool of the Teaching Hospital of Tengandogo (CHU-T) in Burkina Faso
}

\author{
Kain Dantola Paul1, Zamané Hyacinthe², Compaoré Ousséni1, Adediran Sofiath Nancy1, \\ Millogo/Traore Françoise2, Ouédraogo Ali1, Bonané/Thiéba Blandine ${ }^{2}$ \\ ${ }^{1}$ Teaching Hospital of Tengandogo, Ouagadougou, Burkina Faso \\ ${ }^{2}$ Yalgado Ouedraogo Teaching Hospital, Ouagadougou, Burkina Faso \\ Email: zanlotoma@yahoo.fr
}

How to cite this paper: Paul, K.D., Hyacinthe, Z., Ousséni, C., Nancy, A.S., Françoise, M., Ali, O. and Blandine, T. (2021) Cesarean Section Indications and Prognosis in Adolescents Girls at the Mother-Child Pool of the Teaching Hospital of Tengandogo (CHU-T) in Burkina Faso. Open Journal of Obstetrics and Gynecology, 11, 17441751.

https://doi.org/10.4236/ojog.2021.1112163

Received: November 7, 2021

Accepted: December 20, 2021

Published: December 23, 2021

Copyright $\odot 2021$ by author(s) and Scientific Research Publishing Inc. This work is licensed under the Creative Commons Attribution International License (CC BY 4.0).

http://creativecommons.org/licenses/by/4.0/ (c) (i) Open Access

\begin{abstract}
Objective: Conduct a study on cesarean sections in adolescent girls at the mother-child pool of the CHU-T in order to reduce maternal-fetal morbidity and mortality. Patients and Methods: This was a descriptive and cross-sectional study with a retrospective data collection method from January $1^{\text {st }}, 2018$ to December 31 $1^{\text {st }}, 2019$. Results: The frequency of caesarean sections in our series was estimated at $59.9 \%$ in adolescent girls. $68.7 \%$ of adolescent girls were married, the average age was estimated at $18.3 \pm 1$ years, primiparous women were the most represented group with a rate of $88 \%$. Adolescent girls were housewives in $73.5 \%$ of cases, with $37.4 \%$ of them living in rural areas. The main indications for cesarean section were: pre-rupture syndrome (22.9\%), fetal distress (19.3\%), pre-eclampsia/eclampsia (18.1\%) and bony dystocia (21.6\%). The following results derive from the classification of the cesarean section indications into 2 groups according to one or the other member of the "mother-child" couple: maternal indications accounted for $57.8 \%$ while fetal adnexal indications were estimated at $36.1 \%$. As for perinatal mortality, it reached $24.1 \%$. Conclusion: Improving the maternal-fetal prognosis of cesarean section in adolescent girls necessarily requires the strengthening of pregnancies follow-ups among this population group where pregnancy is most often unplanned.
\end{abstract}

\section{Keywords}

Cesarean Section, Adolescent Girls, Indications, Prognosis 


\section{Introduction}

According to the World Health Organization (WHO), nearly 16 million girls aged 15 - 19 and 2 million girls under 15 give birth each year, mostly in low or middle-income countries [1]. According to the same source, pregnancy and childbirth complications are the second leading cause of death in the world among girls aged 15 - 19. Indeed, when an adolescent girl becomes pregnant, her present and future life changes dramatically, rarely for the better, since the risk of these pregnancies is both medical and social [1].

Half of the population of Burkina Faso is under 15 years and a quarter of adolescent girls aged 15 - 19 years have already started their fertile life [2]. The latest report of the Demographic and Health Survey (DHS 2010) indicates that 13\% of adolescent girls in urban areas and $29 \%$ of them in rural areas become mothers for the first time at this age when women have not yet reached maturity [3]. Adolescent pregnancy may be complicated through morbidity and mortality not only because of the immaturity of the adolescent girl's body, but also to particular circumstances such as first pregnancy, low social status, low educational level, unwillingness to become pregnant [4] [5].

Hemorrhage, infection, and dystocia are part of the causes leading to this high mortality. Dynamic and especially mechanical dystocia usually require cesarean delivery. This major obstetric intervention is absolutely useful in the fight against maternal mortality. It is performed either before the onset of labor or during labor or before an obstetric complication; in the latter situation, the cesarean section aims at protecting the mother and/or the fetus from immediate or almost immediate danger [6] [7].

In this paper, we propose a study on cesarean sections in adolescent girls at the mother-child pool of the Teaching Hospital of TENGANDOGO (CHU-T), in order to contribute to the reduction of maternal morbidity and mortality among adolescent girls.

\section{Patients and Method}

Our study took place in Burkina Faso, more specifically in the mother-child pool of the Teaching Hospital of Tengandogo (CHU-T). This was a cross-sectional and descriptive study with a retrospective data collection over a 2 year-period from January $1^{\text {st }}, 2018$ to December $31^{\text {st }}, 2019$. The study population was madeup of all adolescent girls who gave birth in the mother-child pool of the CHU-T during the period of study. The sampling was comprehensive and included all adolescents who went through a cesarean section during our study period within the mother-child pool of CHU-T. Have not been included adolescent girls having an unusable medical folder. Data sources were composed of the following: medical records of the operated adolescent girls, the admissions register, and data from the operating room. Sociodemographic characteristics, medical history, clinical, therapeutic and prognostic aspects were the variables studied. Data were entered and analyzed through Epi Info software version 7.2. 
Ethics Approval: This study was conducted under the supervision of the university JOSEPH KI-ZERBO of Ouagadougou, medical school. We obtained the approval of the Medical Establishment Commission of Tengandogo Teaching Hospital which acts as an ethics committee at the local level. Confidentiality of individual data was ensured at all stages of the study, during the collection and analysis of data through the use of individual and anonymous data collection forms.

\section{Results}

\subsection{Frequency}

During the study period, 152 deliveries were performed in adolescent girls, among which 91 cesarean sections made on adolescent girls in the mother-child pool of the CHU-T. The frequency of cesarean delivery among adolescent girls was 59.8\%. Eighty-three adolescent girls with complete clinical records were included in the study.

\subsection{Sociodemographic Characteristics of Patients}

Table 1 summarizes the age distribution of patients.

Adolescent girls aged 19 years accounted for $51.8 \%$ of the total number of patients. The average age of these patients was $18.3 \pm 1$ years, with ages of 15 and 19 years. Patients living in rural areas represented 53\%. 61 adolescent girls were housewives which correspond to $73.5 \%$. Patients were living a marital relationship in $68.7 \%$. The adolescent girls were not attending school in $37.4 \%$.

\subsection{Admission Mode}

Referrals and/or evacuations were the mode through which 78 patients were admitted in the hospital, corresponding to a rate $94 \%$. However, five patients were directly admitted.

\subsection{Cesarean Section Data}

\subsubsection{Cesarean Data}

Table 2 shows the distribution of patients according to cesarean section indications. Maternal indications accounted for $57.8 \%$ of the cesarean section indications.

Table 1. Age distribution of patients $(n=83)$.

\begin{tabular}{ccc}
\hline Age (in years) & Number (n) & Percentage (\%) \\
15 & 2 & 2.4 \\
16 & 3 & 3.6 \\
17 & 10 & 12 \\
18 & 25 & 30.1 \\
19 & 43 & 51.8 \\
TOTAL & 83 & 100 \\
\hline
\end{tabular}


Table 2. Distribution of patients according to caesarian section $(\mathrm{n}=83)$.

\begin{tabular}{lcc}
\hline \multicolumn{1}{c}{ Indications } & Number (n) & Frequency \\
\hline Maternal indications & 19 & 22.9 \\
Uterine pre rupture & 15 & 18.1 \\
Eclampsia/Preeclampsia & 9 & 10.8 \\
Generally narrowed pelvis & 3 & 3.6 \\
Dynamic Dystocia & 2 & 2.4 \\
Mother's medical conditions & & \\
Fetal-adnexal indications & 16 & 19.3 \\
Acute fetal distress & 7 & 8.4 \\
Vicious presentation & 2 & 2.4 \\
Retro-placental hematoma & 2 & 2.4 \\
Premature rupture of membranes & 1 & 1.2 \\
Multiple pregnancies plus nuchal cord & 1 & 1.2 \\
Nuchal Cord & 1 & 1.2 \\
Premature delivery threat & & 16.8 \\
Maternal-fetal indications & 14 & \\
Fetal-pelvic disproportion & & \\
\hline
\end{tabular}

\subsubsection{Type of Anesthesia}

Local-regional anesthesia was used in $85.5 \%$ of patients $(\mathrm{n}=71)$ while $14.5 \%$ $(n=12)$ of cesarean sections were performed under general anesthesia.

\subsubsection{Caesarian Section Duration}

The average duration of caesarian section was $51 \mathrm{~min} \pm 11.4 \mathrm{~min}$.

\subsection{Prognostic Aspects}

\subsubsection{Maternal Prognostic}

Five patients (6\%) presented complications such as severe anemia (3 cases), bladder injury (1 case) and endometritis (1 case).

No death was recorded during our study period.

\subsubsection{Perinatal Prognosis}

We had registered 85 births among which 83 live births. The average birth weight was $2873.6 \pm 601$ grams. Seventeen newborns $(20.5 \%)$ had a birth weight below $2500 \mathrm{~g}$.

Four newborns corresponding to $5.3 \%$, were resuscitated.

Six neonates were transferred to neonatology for neonatal distress (3 cases), respiratory distress ( 2 cases) and polymal formative syndrome ( 1 case).

Two stillbirths were recorded, corresponding to a stillbirth rate of $24.1 \%$.

\subsection{Hospitalization Duration}

The average hospitalization duration for adolescent girls postoperatively was 3.9 
days \pm 2.3 days.

\section{Discussion}

$\checkmark$ Limitations of Study: Due to retrospective collect of data, we notice the following limitations: the miss data for some of variables.

$\checkmark$ During the study period, the frequency of cesarean section delivery among adolescent girls was estimated at 59.9\%. KAKA [8] in the Democratic Republic of Congo, LENO [9] in Guinea Conakry and FOUMSOU [10] in Chad came up respectively with $38.5 \% ; 29 \%$ and $17.5 \%$ of cesarean section rates among adolescent girls. These high proportions could be explained by the high frequency of dystocia in adolescent girls and particularly the immaturity of the pelvis, combined to adolescent girls' minds who, in most cases, are not yet prepared to give birth.

$\checkmark$ We found an average age of $18.3 \pm 1$ years. Our result is slightly higher than HAMADA's [11] in Morocco who found an average age 17.3 years. Our average age was noticeably above those of ILOKI [12] in Congo-Brazzaville and TRAORE [13] in Mali who respectively found an average age of 14 and 16 years. This could be explained by the particularity of our study, which was focused exclusively on adolescent girls having gone through a cesarean section, unlike ILOKI's which included all adolescent parturients regardless of the mode of delivery. In our study, housewives accounted for $73.5 \%$ while pupils/students accounted for $19.3 \%$. The high proportion of housewives among adolescent girls is consistent with the literature data, a fairly common picture in Africa generally and particularly in Burkina Faso. Forced and early marriages with their corollary of school drop outs could explain this high rate of "housewives" among adolescent girls. $68.7 \%$ of adolescent girls in our study were living a marital relationship. Our results are above those of FOUELIFACK et al. [14] in 2014 and EGBE et al. [15] in 2015 in Cameroon who respectively found frequencies of $20.6 \%$ and $35.8 \%$. The persistence of early marriage can explain this high proportion of married women. Indeed, in Burkina Faso, more than one-third of young women aged 15 to 19 are married. In addition, African traditions and customs do not tolerate pregnancy in an unmarried girl. As a result, there is a high prevalence of early marriages, especially in rural areas, in order to preserve their virginity until marriage. The unschooled patients accounted for 37.3\%. However, LENO [9] in Guinea Conakry and TRAORE [13] in Mali respectively found $54.8 \%$ and $69.2 \%$ of unschooled adolescent girls. This difference could be explained by the site of our study, which took place in an urban area where school enrollment rates are generally higher than in rural areas.

$\checkmark$ In our study, uterine pre-rupture syndrome was the first indication for cesarean sections performed in adolescents. Our result is above that of TOSSOU [16] in 2017 in Burkina Faso who had found 7.7\%. The high rate of pre-rupture syndrome occurrence can be explained in one hand by a delay in eva- 
cuating parturients and on the other hand by a delay in managing obstetrical and surgical emergencies at the CHU-T; indeed, at the CHU-T, the maternity operating room lacks an functional autonomy, since there is a pooling of the operating room personnel such as nurses and resuscitating anesthetists with the central surgical unit. In our series, eclampsia and pre-eclampsia led to perform caesarean section in $18.1 \%$ of cases. KPRAKPRA [6] in Burkina Faso had found a rate of $7 \%$. This situation could be explained by the fact that hypertensive pathology is considerably increasing in developing countries in general and in Burkina Faso particularly where it has become a public health issue. Moreover, our patients' young age and primiparity are the main risk factors for pre-eclampsia. Bone dystocia represented $21.6 \%$ of all indications. This relatively high proportion could be explained in our series by the parturients' young age, i.e. a pelvis still in its growing phase. This rate is lower than that found by BAMBARA [17] in Burkina Faso who had found $37.5 \%$. Indications attributable to the fetus and its appendages accounted for $36.1 \%$ of cesarean sections in adolescent girls. These indications were dominated by fetal suffering, which led to perform cesarean section in $19.3 \%$ of cases. Our results are below to those of TOSSOU [16] in 2017 in Burkina Faso; TCHANTCHOU [18] in Gabon, PETE [7] in 2010 in Ivory Coast and MBONGO [19] in Congo whose rates were respectively $32.97 \%, 48 \%, 58.8 \%$, and $94.2 \%$ of indications cases for acute fetal suffering.

$\checkmark$ The incidence of postoperative complications in our series was estimated at $9.6 \%$. Anemia was the most common postoperative complication with a rate of 3.6\%. Our rate is below the one found by TAPSOABA. Y. [20] which was $64.2 \%$ in 2017 . This high rate of postoperative anemia found in the literature is due to several factors; this anemia is related to the intraoperative blood spoliation but also to the precarious nutritional status and pre-existing anemia in these adolescent girls. We did not record any maternal deaths during the study period while TCHANTCHOU [18] in Gabon and Pete [7] in Côte d'Ivoire respectively reported rates of $0.7 \%$ and $0.9 \%$. In our study, despite the delay in performing obstetrical surgery, the absence of maternal deaths could be explained by the large resuscitation capacities of the CHU-T, particularly with the multipurpose resuscitation unit added to the stakeholders 'quick availability and intervention in case of vital threat. In our series, perinatal mortality was estimated $24.1 \%$. This rate is above the one reported by TAPSOABA [20] in Kaya which was $0.3 \%$. Perinatal mortality in our context remains high despite pediatric assistance and good collaboration between obstetricians and pediatricians. This could be explained by the fact that a great number of perinatal deaths are found among newborns coming from elsewhere after having gone through the neonatology units of the city center without obtaining any place; thus they arrive most often in a severe infectious state. Thus, the high neonatal mortality during our study period led to suspend activities and to thoroughly clean and disinfect the neonatology unit. 


\section{Conclusion}

Improving the maternal-fetal prognosis of cesarean section in adolescent girls necessarily requires the strengthening of pregnancies follow-ups among this population group where pregnancy is most often unplanned.

\section{Conflicts of Interest}

The authors declare no conflicts of interest regarding the publication of this paper.

\section{References}

[1] OMS (2010) Santé de la mère du nouveau-né de l'enfant et de l'adolescent [Maternal, Newborn, Child and Adolescent Health]. https://www.who.int/maternal child adolescent/topics/adolescence/dev/fr/

[2] Thieba, B., Akotionga, M., Ouattara, T., Ouedraogo, A., Lankoande, J. and Kone, B. (2002) Adolescentes et urgences gynéco-obstétricales à Ouagadougou [Adolescent Girls and Gynecological-Obstetrical Emergencies in Ouagadougou]. Journal de la $S A G O, 1,7-110$.

[3] Institut national de la statistique et de la démographie (INSD) and ICF International. (2010) Enquête démographique et de santé et à indicateurs multiples, Burkina Faso [Demographic and Health and Multiple Indicator Survey, Burkina Faso].

[4] Luhete, P.K., Mukuku, O., Tambwe, A.M. and Kayamba, P.K.M. (2017) Etude du pronostic maternel et périnatal au cours de l'accouchement chez l'adolescente à Lubumbashi, République Démocratique du Congo [Study of Maternal and Perinatal Prognosis during Adolescent Delivery in Lubumbashi, Democratic Republic of Congo]. Pan African Medical Journal, 26, Article No. 182.

[5] Soula, O., Carles, G., Largeaud, M., El Guindi, W. and Montoya, Y. (2006) Grossesses et accouchement chez les adolescentes de moins de 15 ans [Montoya Pregnancy and Delivery in Adolescent Girls under 15 Years]. Journal de Gynécologie Obstétrique et Biologie de la Reproduction, 35, 53-61.

[6] Kprakpra, G.M. (2007) Les indications de la césarienne dans le service de gynécologie-obstétrique du Centre Hospitalier Universitaire Yalgado Ouédraogo. Burkina Faso [Cesarean Section Indications in the Gynecology-Obstetrics Department of the Teaching Hospital Yalgado Ouédraogo. Burkina Faso]. These Med Université de Ouagadougou, $\mathrm{N}^{\circ} 1137,98$.

[7] Pete, Y.D.D., Ouattara, A., Koffi, N., Abhé, C., Sanou, J., Itéké, F. and Kané, M. (2012) Césariennes en urgence: Pronostic materno-foetal au CHU de Cocody d'Abidjan [Emergency Caesarean Sections: Maternal-Fetal Prognosis at the Cocody Teaching Hospital in Abidjan]. Revue Africaine d Anesthésiologie et de Médecine d Urgence (RAMUR), 17, 60-65.

[8] Kaka, J.C. and Kabakele, A. (2014) Congo-Kinshasa Issues d'accouchement chez les adolescentes au Centre Mère-Enfant de Bumbu à Kinshasa (République Démocratique du Congo) [Congo-Kinshasa Outcomes of Childbirth in Adolescents at the Mother-Child Center of Bumbu in Kinshasa (Democratic Republic of Congo)]. Médecine d Afrique Noire, No. 6106, 289-296.

[9] Leno, D.W.A., Camara, A.Y., Bah, E.M., Toure, S., Tolno, J., Lamah, D. and Keita, N. (2018) Guinée Maternités des adolescentes au Centre Hospitalier Universitaire de Conakry en Guinée. Profil socio-démographique et obstétrical [Guinea Adolescent Maternities at the Teaching Hospital Center of Conakry in Guinea. SocioDemographic and Obstetrical Profile]. Médecine d Afrique Noire, No. 6503, $157-$ 163. 
[10] Foumsou, L., Gabkika, B.M., Saleh, A. and Memadji, M. (2014) Tchad Les complications obstétricales chez les adolescentes à la maternité de l'hôpital général de référence nationale (HGRN) de N'Djamena [Chad Obstetrical Complications in Adolescent Girls at the Maternity Ward of the National General Reference Hospital (HGRN) in N'Djamena]. Médecine d Afrique Noire, No. 6109, 441-447.

[11] Hamada, H., Zaki, A., Nejjar, H., Filali, A., Chraibi, C., Bezad, R. and Taheralaoui, M. (2004) Grossesse et accouchement chez l'adolescente: Caractéristiques et profil à propos de 311 cas [Adolescent Pregnancy and Delivery: Characteristics and Profile about 311 Cases]. Journal de Gynécologie Obstétrique et Biologie de la Reproduction, 33, 607-614.

[12] Iloki, L.H., Koubaka, R., Itoua, C. and Mbembamoutounou, G.M. (2004) Grossesse et accouchement chez l'adolescente au Congo, à propos de 276 cas au CHU de Brazzaville [Adolescent Pregnancy and Childbirth in Congo, about 276 Cases at the Teaching Hospital of Brazzaville]. Journal de Gynécologie Obstétrique et Biologie de la Reproduction, 33, 37-42.

[13] Traore, B., Thera, T., Kokaina, C., Beye, S.A., Mounkoro, N., Teguete, I., Traore, M. and Dolo, A. (2010) Mali Accouchement chez les adolescentes à la maternité du Centre Hospitalier Régional de Ségou au Mali: Pronostic obstétrical et néonatal [Mali ,Adolescent delivery in the maternity ward of the Regional Hospital Center of Ségou in Mali: obstetrical and neonatal prognosis]. Médecine d Afrique Noire, No. 5710, 449-454.

[14] Fouelifack, F.Y., Tameh, T.Y., Mbong, E.N., et al. (2014) Outcome of Deliveries among Adolescent Girls at the Yaoundé Central Hospital. BMC Pregnancy and Childbirth, 14, Article No. 102. https://doi.org/10.1186/1471-2393-14-102

[15] Egbe, T.O., Omeichu, A., Halle-Ekane, G.E., et al. (2015) Prevalence and Outcome of Teenage Hospital Births at the Buea Health District, South West Region, Cameroon. Reproductive Health, 12, Article No. 118.

https://doi.org/10.1186/s12978-015-0109-5

[16] Tossou, S.O. (2016) Particularités de la grossesse et de l'accouchement chez les adolescentes: Th Mèd Univ Joseph KI ZERBO [Peculiarities of Adolescent Girls Pregnancy and Childbirth: Th Mèd Univ Joseph KI ZERBO]. N5, 66.

[17] Bambara, M., Fontane, E., Dao, B., Ouattara, S., Ouattara, H. and Lankoande, J. (2007) La césarienne en milieu africain: À propos de 440 cas à la maternité du CHUSS de Bobo-Dioulasso (Burkina Faso) [Caesarean Section in African Setting: about 440 Cases at the Maternity Hospital of Soro Sanou Teaching Hospital of Bobo-Dioulasso (Burkina Faso)]. Médecine d' Afrique Noire, 54, 344-348.

[18] Tchantchou, D.D., Bang Ntamack, J.A., Sima Olé, B., Mpiga Ndjambou, E., Pither, S. and Meye, J.F. (2020) Césarienne d'Urgence à la Maternité de l'Hôpital d'Instruction des Armées Omar Bongo Ondimba de Libreville: Délais de Réalisation et Facteurs de Retard [Emergency Caesarean Section at the Maternity Hospital of the Omar Bongo Ondimba Armed Forces of Libreville: Time of Performance and Factors of Delay]. Health Sciences and Disease, 21, 51-56.

[19] Mbongo, J.A., Butoyi, J., Papandi-Ikourou, A. and Iloki, L. (2016) Césarienne en urgence au Centre Hospitalier et Universitaire de Brazzaville [Emergency Cesarean Section at the Teaching Hospital of Brazzaville]. Health Sciences and Disease, 17, No. 1.

[20] Tapsoba, W.Y. (2018) Evaluation des indications de césarienne selon la classification de Robson à la maternité du CHR de Kaya du 1er Janvier 2017 au 31 Décembre 2017 [Evaluation of the Caesarean Section Indications According to Robson's Classification at the Maternity Ward of the Regional Hospital Center of Kaya from 1st January, 2017 to 31st, December, 2017]. Université Saint Thomas d'Aquin, Ouagadougou, $148 \mathrm{p}$. 